\title{
The teeth of the unenlagiine theropod Buitreraptor from the Cretaceous of Patagonia, Argentina, and the unusual dentition of the Gondwanan dromaeosaurids
}

Federico A. Gianechini, Peter J. Makovicky, and Sebastián Apesteguía

Acta Palaeontologica Polonica 56 (2), 2011: 279-290 doi: http://dx.doi.org/10.4202/app.2009.0127

The Unenlagiinae is a clade of Gondwanan dromaeosaurid theropods mainly known from incomplete skeletal material. The group includes two recently discovered theropods, Buitreraptor and Austroraptor, from which cranial remains are available with in situ maxillary and dentary teeth, thus allowing the study of tooth morphology. Among the derived traits that diagnose the dentition of unenlagiines are: (i) high tooth count, (ii) small size of individual teeth when compared with skull height, (iii) absence of denticles and carinae, and (iv) presence of longitudinal grooves on the tooth crown. This suite of dental characteristics, shared between Buitreraptor and Austroraptor, can be considered as diagnostic of the Unenlagiinae or, at least, a more exclusive clade within the group. The teeth of Buitreraptor exhibit a remarkable labiolingual compression, whereas Austroraptor possesses more conical teeth, probably respective autapomorphic features. On one hand, these dental morphologies differ from those observed in most Laurasian dromaeosaurids and, for instance, could be considered as further proof of the purported vicariant evolution of the lineage on the southern continents. On the other hand, the morphological similarities (e.g., absence of denticles) between the teeth of unenlagiines and other theropod lineages, including Mesozoic birds and ornithomimosaurs, can be considered as the result of parallel trends related to dental reduction.

Key words: Dinosauria, Theropoda, Dromaeosauridae, Unenlagiinae, teeth, Cretaceous, Argentina.

Federico A. Gianechini [smilodon.80@gmail.com] and Sebastián Apesteguía [sebapesteguia@gmail.com], CONICET. Fundación de Historia Natural 'Félix de Azara' - CEBBAD - Universidad Maimónides. Hidalgo 775, $7^{\circ}$ piso (1405BDB), Buenos Aires, Argentina; Peter J. Makovicky [pmakovicky@fieldmuseum.org], Field Museum of Natural History, 605 South Lake drive, Chicago, USA. 
This is an open-access article distributed under the terms of the Creative Commons

Attribution License (for details please see creativecommons.org), which permits unrestricted use, distribution, and reproduction in any medium, provided the original author and source are credited.

\author{
For Full text $(457.5 \mathrm{kB})$ । \\ FDF
}

